\title{
Relationships between impulse oscillometry, spirometry and dyspnoea in COPD
}

${ }^{2}$ WJ Anderson, ${ }^{2} \mathrm{BJ}$ Lipworth

${ }^{1}$ Clinical Research Fellow; ${ }^{2}$ Professor of Allergy and Pulmonology; Asthma and Allergy Research Group, University of Dundee, Dundee, Scotland, UK

\section{ABSTRACT}

Background: Severity of chronic obstructive pulmonary disease (COPD) is based either on symptoms/disability or lung function, which have no discernible correlation. We hypothesised that impulse oscillometry (IOS), a non-effortdependent measure of central and peripheral airway mechanics, could correlate to dyspnoea in COPD.

Methods: We analysed screening data from 57 COPD patients who had spirometry, IOS and Medical Research Council dyspnoea score (MRC) measurements. We searched for predictors or correlations of MRC from IOS, spirometry and demographics.

Results: MRC had no significant predictors or correlations from IOS, spirometry or demographics (possibly excepting smoking history, $\mathrm{p}=0.05$ ). IOS correlated significantly with spirometry: FEVI and FEF25-75 vs. R5-R20 (peripheral airway resistance), $r=-0.499, p<0.001$ and $r=-0.397, p=0.002$ respectively.

Conclusion: MRC is not related to IOS or spirometry in COPD. IOS correlates well with spirometry, particularly peripheral airway resistance (R5-R20). IOS is useful, but does not provide a link between symptoms and pulmonary function measurements.

KEYWORDS Medical Research Council score, chronic obstructive pulmonary disease, Impulse oscillometry, spirometry, correlation

DECLARATION OF INTERESTS No conflicts of interest declared.
Correspondence to BJ Lipworth Asthma and Allergy Research Group, University of Dundee, Dundee DDI 9SY, UK

tel. $+44(0) 1382632983$ e-mail brianlipworth@gmail.com

\section{INTRODUCTION}

Chronic obstructive pulmonary disease (COPD) is a major, worldwide, largely smoking-related condition associated with a significant burden of morbidity and mortality.' It is highly variable both in terms of clinical expression and underlying pathological abnormality with the two not necessarily related. ${ }^{2}$ Methods of classifying severity of COPD must therefore encompass this variability in some way but at the same time reliably reflect the overall severity of disease. This is important because it is these classifications that are used to determine treatment as well as predicting likelihood of survival from COPD. Despite this, most classifications of COPD concentrate either on symptoms/disability (e.g. Medical Research Council [MRC] dyspnoea scale) ${ }^{3}$ or lung function (e.g. Global initiative for chronic obstructive lung disease [GOLD] $)^{4}$ or British Thoracic Society (BTS) guidelines). ${ }^{5}$ More recently the BODE index ${ }^{6}$ which includes: body mass index, lung function, dyspnoea and exercise capacity has come some way to addressing the overall assessment of COPD severity. However, this is still limited to predicting mortality alone, without addressing distinct levels of clinical severity.

Impulse oscillometry (IOS) is a non-effort-dependent pulmonary investigation that provides information about airway mechanics - airway resistance and reactance (a measure of compliance) - at multiple levels throughout the bronchial tree. It is used as an aid to the diagnosis of obstructive pulmonary diseases, mainly asthma and COPD. It requires only tidal breathing to perform, while the equipment applies distinct oscillatory frequencies through a mouthpiece to the bronchial tree that are generated by what is essentially a loudspeaker - one analogy is 'bronchial sonar'. Specific frequencies relate to different levels through the bronchial tree: a frequency of 5 hertz $(\mathrm{Hz})$ provides values for total airway resistance (R5) and reactance (X5); a $20 \mathrm{~Hz}$ frequency gives a value for central or large airway resistance (R20); and if one subtracts the value of central airway resistance from that for total airway resistance (i.e. R5-R20), this provides a measure of peripheral or small airways resistance. Increasing values of airway resistance relate to worsening obstruction at each of these anatomical levels.

Impulse oscillometry has previously been found to be a sensitive measure of small airways function in both asthma ${ }^{7}$ and COPD. ${ }^{8}$ Indeed it is more sensitive in terms of assessing bronchodilation than spirometry alone. ${ }^{9,10}$ In children with asthma, abnormal IOS measurements also correlate with poor asthma control. ${ }^{11,12}$ However, IOS measurements are subject to more variability both within and between subjects (coefficient of variability 
[Cv] approximately 10\%) with COPD than spirometry (Cv 2-3\%) ${ }^{13-15}$ although it has been shown to remain fairly constant over three months. ${ }^{8}$ This suggests that IOS cannot currently replace spirometry in the diagnosis of COPD, but is a useful confirmatory adjunctive test that is easy to perform. ${ }^{16}$

The MRC dyspnoea scale has been validated in categorising the degree of disability afforded COPD patients due to breathlessness ${ }^{17}$ - i.e. clinically relevant - but this was not associated with forced expiratory volume in one second (FEVI). Given that IOS can measure small (peripheral) airways function in COPD, ${ }^{18}$ we hypothesised that this in particular could be more closely related to degree of breathlessness as measured by the MRC dyspnoea scale in COPD patients than standard spirometry, thus providing a tenable link between symptoms and the pathophysiology of pulmonary function when categorising the severity of COPD.

\section{METHODS}

We prospectively collected data from single centre screening visits of consecutive COPD patients who attended from primary care to our research department between 2009-20II. The diagnosis of COPD was confirmed by a respiratory physician based on clinical history and spirometry. Chronic obstructive pulmonary disease was defined as fixed airflow obstruction (FEVI/ FVC [forced vital capacity] ratio $<70 \%$, and $<15 \% \mathrm{FEVI}$ reversibility following 400 micrograms [ $\mu \mathrm{g}]$ salbutamol) with a current or past history of smoking ( $\geq 10$ packyears). Each individual had given their consent for their information to be held in our database and used for research purposes. Ethical approval was granted by Tayside Medical Research Ethics Committee.

Patients undertook IOS followed by spirometry (to avoid disturbance of IOS measurements) at the same screening visit. Each patient recorded their degree of breathlessness according to the MRC dyspnoea scale:

I. Not troubled by breathlessness except on strenuous exercise.

2. Short of breath when hurrying or walking up a slight hill.

3. Walks slower than contemporaries on level ground because of breathlessness, or has to stop for breath when walking at own pace.

4. Stops for breath after walking about $100 \mathrm{~m}$ or after a few minutes on level ground.

5. Too breathless to leave the house or breathless when dressing or undressing.

Baseline demographics were also recorded including: age, gender, body mass index (BMI), current smoking status and smoking history (pack-years).
Patients were also classified by GOLD stage:

I. Mild FEVI/ FVC ratio $<70 \%$, FEVI $\geq 80 \%$.

2. Moderate FEVI/FVC $<70 \%, 50 \% \leq \mathrm{FEVI}<80 \%$.

3. Severe FEVI/FVC $<70 \%, 30 \% \leq \mathrm{FEVI}<50 \%$.

4. Very severe FEVI/FVC $<70 \%$, FEVI $<30 \%$ or associated chronic respiratory failure or right heart failure.

\section{Study measurements}

Impulse oscillometry was performed in accordance with manufacturer's guidelines. A SuperSpiro spirometer was used to perform spirometry in accordance with European Respiratory Society (ERS) guidelines. ${ }^{19}$

\section{Statistical analysis}

All data were checked for normality of distribution prior to analysis. Any data that could not achieve a normal distribution with transformation were analysed using the equivalent non-parametric statistical tests. Primary analysis was performed using ordinal logistic regression with MRC dyspnoea scale (ordinal categorical variable) as the dependent variable and covariates that represented outcome measures (age, BMI, gender, pack-years smoking history, FEVI and R5) to generate a model. Secondary correlation analyses were performed using either Pearson's or Spearman's rho tests for all outcome variables based on whether they were parametric or non-parametric variables respectively.

\section{RESULTS}

Fifty-seven COPD patients who had both spirometry and IOS measurements at screening as well as having recorded a MRC dyspnoea score were identified. They had a mean age of 66.4 years, $58 \%$ were male, median GOLD stage was two, with a median MRC score of two. The remaining patient demographics are presented in Table I.

Ordinal logistic regression with MRC dyspnoea scale as the dependent variable could not demonstrate a useful model to describe it using the following representative covariates: age, $\mathrm{BMI}$, gender, pack-years smoking history, FEVI or R5 (model pseudo $R^{2}=0.111, p=0.392$ ). At the level of individual covariates, pack-years smoking history was the only one potentially predictive of MRC dyspnoea scale $(p=0.05)$ but was not a powerful enough predictor on its own to affect the overall model. The MRC dyspnoea scale did not directly correlate (Spearman's rho) with any IOS variables, spirometry or demographics (including pack-years smoking history) (Table 2).

However, significant direct correlations (Pearson's) were found between IOS and spirometry variables as presented in Table 3. Strong correlations were found between R5 (total airway resistance) with FEVI, FVC and Forced Expiratory Fraction (FEF) between 25-75\% of FVC (FEF 25-75). Also R5-R20 (peripheral airway 
TABLE I Demographics and pulmonary function of chronic obstructive pulmonary disease patients

\begin{tabular}{|c|c|}
\hline Variable & $n=57$ \\
\hline \multicolumn{2}{|l|}{ Demographics } \\
\hline Age (years) & $66.4(63.8,68.9)$ \\
\hline Sex (male \%) & 57.9 \\
\hline BMI $\left(\mathrm{kg} / \mathrm{m}^{2}\right)$ & $26.5(25.3,27.7)$ \\
\hline Smoking status (current \%) & 40.4 \\
\hline Smoking history (pack-years) & $45.3(39.3,51.3)$ \\
\hline MRC dyspnoea scale (median, IQR) & $2(2,3)$ \\
\hline MRC dyspnoea scale (groups I-5) \% & $14,44,23,14,5$ \\
\hline \multicolumn{2}{|l|}{ Spirometry } \\
\hline FEVI (L) & $1.37(1.22,1.53)$ \\
\hline FEVI \% predicted & $53.8(49.1,58.5)$ \\
\hline FVC (L) & $2.39(2.18,2.61)$ \\
\hline FEF 25-75 (L) & $0.77(0.65,0.89)$ \\
\hline FEVI/FVC ratio & $57.4(54.1,60.8)$ \\
\hline GOLD stage (median, IQR) & $2(2,3)$ \\
\hline GOLD stage (groups I-4) \% & $3.5,42.1,38.6,7.0$ \\
\hline \multicolumn{2}{|l|}{ Impulse oscillometry } \\
\hline $\mathrm{R} 5$ (kPa/L/sec) & $0.61(0.55,0.67)$ \\
\hline R5 \% predicted & $177.4(160.6,194.2)$ \\
\hline $\mathrm{R} 20(\mathrm{kPa} / \mathrm{L} / \mathrm{sec})$ & $0.38(0.35,0.4 \mathrm{I})$ \\
\hline $\mathrm{X} 5(\mathrm{kPa} / \mathrm{L} / \mathrm{sec})$ & $-0.33(-0.38,-0.28)$ \\
\hline $\mathrm{R} 5-\mathrm{R} 20(\mathrm{kPa} / \mathrm{L} / \mathrm{sec})$ & $0.23(0.19,0.28)$ \\
\hline \multicolumn{2}{|c|}{ 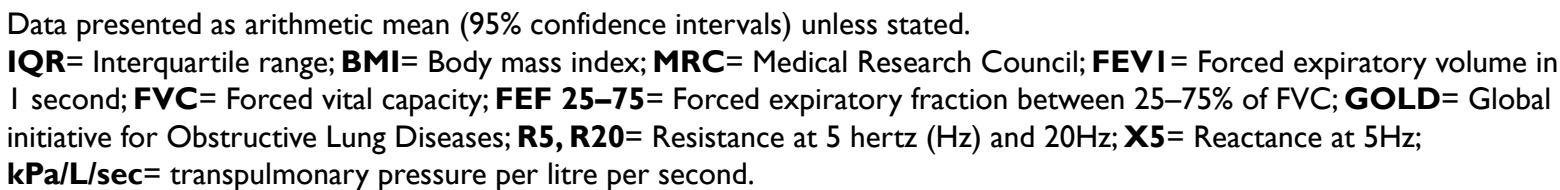 } \\
\hline
\end{tabular}

resistance) vs. FEVI $(R=-0.499, \mathrm{p}<0.00 \mathrm{I}), \mathrm{R} 5-\mathrm{R} 20$ vs. FVC $(R=-0.521, P<0.001)$ and $R 5-R 20$ vs. FEF $25-75$ $(R=-0.397, p=0.002)$ correlated significantly. There were no correlations between central airway resistance (R20) and any spirometric variable.

\section{DISCUSSION}

We have not demonstrated any significant relationship between MRC dyspnoea scale and IOS in COPD patients either by using regression modelling or through direct correlation testing. None of the spirometric or demographic variables were correlated with MRC either, with the possible exception of a trend towards packyears smoking history as a predictor of MRC.

There have been a number of different systems developed in an effort to help classify the severity of COPD. These have been largely based on symptoms (e.g. MRC dyspnoea scale) or lung function (GOLD stage), with the two seemingly operating independently of each other. ${ }^{6,20}$ There has been no good COPD severity grading system that draws on the benefits of measuring disability through symptoms in addition to correlating with objective measures of lung function, although using the two synchronously for patient assessment is likely to be more useful. ${ }^{21}$ The BODE index ${ }^{6}$ has come some way to achieving this but it still mainly predicts mortality rather than providing a true 'day-to-day' link between symptoms and lung function. We hypothesised that IOS may provide this elusive connection in COPD by being a measure of small airways function sensitive to more subtle changes in airflow dynamics at that level and thus bear a greater relationship to symptoms - breathlessness in particular.

Our finding of a lack of correlation between MRC dyspnoea scale and IOS is in contrast to the findings of a recent similar study by Haruna et al. examining peripheral lung function and patient reported outcomes in 65 male COPD patients. ${ }^{22}$ They found that the IOS variable R5-20, thought to most accurately reflect peripheral airways resistance, was moderately correlated with both the St George's Respiratory Questionnaire (SGRQ) and the MRC dyspnoea scale to a similar degree in their cohort. Overall, their cohort had milder 
TABLE 2 Correlation of MRC dyspnoea scale with IOS, spirometry and demographics of chronic obstructive pulmonary disease patients

\begin{tabular}{|c|c|c|}
\hline & \multicolumn{2}{|c|}{ MRC dyspnoea scale } \\
\hline Variable $(n=57)$ & $\mathbf{r}$ & p-value \\
\hline Age (years) & -0.089 & 0.512 \\
\hline BMI $\left(\mathrm{kg} / \mathrm{m}^{2}\right)$ & 0.114 & 0.398 \\
\hline Smoking history (pack-years) & 0.145 & 0.280 \\
\hline Current smoking status & -0.194 & 0.149 \\
\hline FEVI (L) & -0.104 & 0.442 \\
\hline FVC (L) & -0.137 & 0.309 \\
\hline FEF $25-75$ (L) & -0.004 & 0.977 \\
\hline FEVI/FVC ratio & -0.024 & 0.858 \\
\hline GOLD stage $(0-4)$ & 0.112 & 0.407 \\
\hline R5 (kPa/L/sec) & 0.155 & 0.250 \\
\hline R20 (kPa/L/sec) & 0.161 & 0.232 \\
\hline $\mathrm{X} 5(\mathrm{kPa} / \mathrm{L} / \mathrm{sec})$ & -0.108 & 0.427 \\
\hline R5-R20 (kPa/L/sec) & 0.103 & 0.448 \\
\hline \multicolumn{3}{|c|}{ 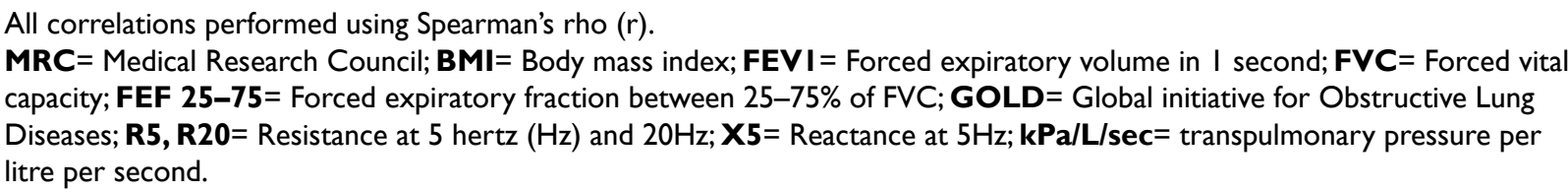 } \\
\hline
\end{tabular}

disease than our patients (FEVI= I.64L cf. I.37L) and less in the way of symptoms (Mean MRC $=I . I$, cf. median $M R C=2)$. They also had fewer current smokers $(17 \%$ cf. $40 \%$ ) and no mention of overall smoking history in packyears. It may therefore be that certain correlations in one 'population' of COPD patients may not be true for others i.e. no clear overarching link between symptoms and IOS in all COPD patients. Indeed, whether IOS has a more direct link to symptoms in the early stages of COPD requires further evaluation.

Our findings are in agreement with previous studies that have failed to demonstrate any significant relationship between dyspnoea score and spirometry (FEVI). ${ }^{17}$ This lack of correlation may be due to the fact that we have performed static measurement, single time point analysis here, whereas it has previously been reported that changes in trough FEVI post- bronchodilator is negatively correlated to change in SGRQ over time, and that the strength of the correlation increases over three, six, nine and 12 months. ${ }^{23}$ Equally, patients' symptoms tend to be more variable day-to-day than their spirometry, requiring a more longitudinal analysis of this relationship. Longitudinal analyses of multiple outcomes in COPD are currently underway with the Evaluation of COPD Longitudinally to Identify Predictive Surrogate Endpoints (ECLIPSE) trial. ${ }^{24}$

We have confirmed previous work ${ }^{18,25}$ demonstrating that IOS is significantly correlated to spirometry. FEVI and FVC both correlate well in our cohort with total airway resistance (R5) as well as the peripheral airway measures Reactance at $5 \mathrm{~Hz}(\mathrm{X} 5)$ and R5-R20 in our cohort. FEF 25-75, which itself is considered to reflect small airway closure, only correlated with R5 and R5R20 and that to a lesser degree than FEVI and FVC. R20,

TABLE 3 Correlation of spirometry with impulse oscillometry in chronic obstructive pulmonary disease patients

\begin{tabular}{|c|c|c|c|c|c|c|c|c|}
\hline \multirow{2}{*}{$\begin{array}{c}\text { Variable } \\
n=57\end{array}$} & \multicolumn{2}{|c|}{ R5 (kPa/L/sec) } & \multicolumn{2}{|c|}{ R20 (kPa/L/sec) } & \multicolumn{2}{|c|}{ X5 (kPa/L/sec) } & \multicolumn{2}{|c|}{ R5-R20 (kPa/L/sec) } \\
\hline & $r$ & p-value & $r$ & p-value & $\mathbf{r}$ & p-value & $r$ & p-value \\
\hline FEVI (L) & $-0.426 * *$ & 0.001 & -0.093 & 0.492 & $0.276 *$ & 0.04 & $-0.499 * *$ & $<0.001$ \\
\hline FVC (L) & $-0.487 * *$ & $<0.001$ & -0.192 & 0.153 & $0.47 I^{* *}$ & $<0.001$ & $-0.521 * *$ & $<0.001$ \\
\hline FEF $25-75$ & $-0.305^{*}$ & 0.022 & 0.001 & 0.995 & 0.135 & 0.324 & $-0.397 * *$ & 0.002 \\
\hline FEVI/FVC ratio & -0.076 & 0.573 & 0.087 & 0.519 & -0.158 & 0.243 & -0.151 & 0.262 \\
\hline
\end{tabular}

All correlations performed using Pearson's test.

*Significant at $\mathrm{p}<0.05$; **Significant at $\mathrm{p}<0.0 \mathbf{1} ; \mathbf{F E V ~ I = ~ F o r c e d ~ e x p i r a t o r y ~ v o l u m e ~ i n ~ I ~ s e c o n d ; ~ F V C = ~ F o r c e d ~ v i t a l ~ c a p a c i t y ; ~}$ FEF 25-75= Forced expiratory fraction between 25-75\% of FVC; R5, R20= Resistance at 5 (hertz) $\mathrm{Hz}$ and 20Hz;

X5 $=$ Reactance at $5 \mathrm{~Hz}$. 
which is theorised to represent larger airways, was not correlated with any spirometric variable as shown previously ${ }^{25}$ which certainly points to the smaller peripheral airways being of greater importance in the pathophysiology of COPD. Furthermore, statistically it would appear that the relative proportional contributions played by R5 and R20 in the composite measure R5-R20 are heavily in favour of R5 because of the similar correlations found using both R5 and R5-R20 with spirometric variables. The main strength of the present study is that this is a 'real-life' cross-sectional cohort of COPD patients from the community, on standard community-prescribed medications, with demographics representative of the general population in terms of their disease severity and almost equal numbers of men and women. The most relevant limitations to the study are small numbers of patients, lack of accurate inhaler

\section{REFERENCES}

I Mannino DM. COPD: epidemiology, prevalence, morbidity and mortality, and disease heterogeneity. Chest 2002; 121:12IS-6S. http://dx.doi.org/I0.1378/chest.121.5_suppl.12IS

2 de Torres JP, Bastarrika G, Zagaceta J et al. Emphysema presence, severity, and distribution has little impact on the clinical presentation of a cohort of patients with mild to moderate COPD. Chest 20II; 139:36-42. http://dx.doi.org//0.1378/chest. 10-0984

3 Fletcher CM. Standardised questionnaire on respiratory symptoms: a statement prepared and approved by the MRC committee on the aetiology of chronic bronchitis (MRC breathlessness score). BM] 1960; 2:1665.

4 Global Initiative for Chronic Obstructive Lung Disease. Global strategy for the diagnosis, management and prevention of COPD (GOLD) [Internet]. Spain: Global Initiative for Chronic Obstructive Lung Disease; 2010 [cited 2012 May 18]. Available from: http:// www.goldcopd.org/

5 National Clinical Guidance Centre. Chronic obstructive pulmonary disease: management of chronic obstructive pulmonary disease in adults in primary and secondary care [Internet]. London: National Clinical Guideline Centre; 2010 [cited 2012 May 18]. Available from: http://guidance.nice.org.uk/CGI0I/Guidance/pdf/English

6 Celli BR, Cote CG, Marin JM et al. The body-mass index, airflow obstruction, dyspnea, and exercise capacity index in chronic obstructive pulmonary disease. N Engl J Med 2004; 350:1005-12. http://dx.doi.org/I0.1056/NEJMoa02 I322

7 Yamaguchi M, Niimi A, Ueda T et al. Effect of inhaled corticosteroids on small airways in asthma: investigation using impulse oscillometry Pulm Pharmacol Ther 2009; 22:326-32. http://dx.doi.org//0.1016/j. pupt.2009.01.005

8 Crim C, Celli B, Edwards LD et al. Respiratory system impedance with impulse oscillometry in healthy and COPD subjects: ECLIPSE baseline results. Respir Med 201I; 105:1069-78. http://dx.doi. org/l0.1016/j.rmed.2011.01.010

9 Nair A, Ward J, Lipworth BJ. Comparison of bronchodilator response in patients with asthma and healthy subjects using spirometry and oscillometry. Ann Allergy Asthma Immunol 2011; 107:3 17-22. http://dx.doi.org//0.1016/j.anai.2011.07.011

10 Dellaca RL, Pompilio PP,Walker PP et al. Effect of bronchodilation on expiratory flow limitation and resting lung mechanics in COPD. Eur Respir J 2009; 33:1329-37. http://dx.doi.org/10.1 I83/09031936.00139608

II Shi Y,Aledia AS, Tatavoosian AV et al. Relating small airways to asthma control by using impulse oscillometry in children.J Allergy Clin Immunol 2012; I29:67|-8. http://dx.doi.org/I0.10|6/j.jaci.20I I.II.002

12 Larsen GL, Morgan W, Heldt GP et al. Impulse oscillometry versus spirometry in a long-term study of controller therapy for pediatric asthma.J Allergy Clin Immunol 2009; 123:86I-7. el. therapy data and a disproportionately large number of patients in the MRC two dyspnoea score category which might have biased the results.

In conclusion there is no correlation between the MRC dyspnoea scale and IOS in COPD patients. In addition, the MRC dyspnoea scale does not correlate with spirometry (GOLD stage). IOS correlates well with spirometry, in particular the small (peripheral) airways measure R5-R20.Thus, despite the increasing use of IOS as a simple, non-effort dependent measure of lung function in COPD, it does not bring us any closer to describing the relationship between symptoms and pulmonary function in this debilitating disease. Further longitudinal studies examining this question are urgently required and indeed are already underway.

I3 Neild JE, Twort $\mathrm{CH}$, Chinn S et al. The repeatability and validity of respiratory resistance measured by the forced oscillation technique. Respir Med 1989; 83:III-8. http://dx.doi.org//0.1016/ S0954-6 I I I(89)80224-0

14 Gimeno F, van der Weele LT, Koeter GH et al. Variability of forced oscillation (Siemens Siregnost FD 5) measurements of total respiratory resistance in patients and healthy subjects. Ann Allergy 1993; 71:56-60.

15 van den Elshout FJ, van de Woestijne KP, Folgering HT.Variations of respiratory impedance with lung volume in bronchial hyperreactivity. Chest 1990; 98:358-64. http://dx.doi.org/10.1378/chest.98.2.358

16 Cooper CB.Assessment of pulmonary function in COPD. Semin Respir Crit Care Med 2005;26:246-52.http://dx.doi.org/I0.1055/s-2005-869543

17 Bestall JC, Paul EA, Garrod R et al. Usefulness of the Medical Research Council (MRC) dyspnoea scale as a measure of disability in patients with chronic obstructive pulmonary disease. Thorax 1999; 54:58|-6. http://dx.doi.org//0.1 I36/thx.54.7.581

18 Williamson PA, Clearie K, Menzies D et al. Assessment of smallairways disease using alveolar nitric oxide and impulse oscillometry in asthma and COPD.Lung 20 I I; I89: I 2 I-9. http://dx.doi.org/ I0.1007/ s00408-0I0-9275-y

19 Miller MR, Hankinson J, Brusasco V et al. Standardisation of spirometry. Eur Respir J 2005; 26:3 19-38. http://dx.doi.org/I0.1 I83/090 31936.05.00034805

20 Nishimura K, Izumi T, Tsukino $M$ et al. Dyspnea is a better predictor of 5-year survival than airway obstruction in patients with COPD. Chest 2002; I21:1434-40. http://dx.doi.org//0.1378/ chest. I2I.5.1434

21 Braido F, Baiardini I, Menoni S et al. Disability in COPD and its relationship to clinical and patient-reported outcomes. Curr Med Res Opin 20II; 27:98I-6. http://dx.doi.org/I0.I I85/03007995.20I I.563285

22 Haruna A, Oga T, Muro S et al. Relationship between peripheral airway function and patient-reported outcomes in COPD: a cross-sectional study. BMC Pulm Med 2010; 10:10. http://dx.doi. org/I0.1I86/I47I-2466-10-10

23 Westwood M, Bourbeau J, Jones PW et al. Relationship between FEVI change and patient-reported outcomes in randomised trials of inhaled bronchodilators for stable COPD: a systematic review. Respir Res 20 I I; I2:40. http://dx.doi.org/ I0.I I86/ I465-992 I-I2-40

24 Vestbo J, Anderson W, Coxson $\mathrm{HO}$ et al. Evaluation of COPD Longitudinally to Identify Predictive Surrogate End-points (ECLIPSE). Eur Respir J 2008; 31:869-73. http://dx.doi.org/ I0.I I83/0903 I936.00 I I I707

25 Kolsum U, Borrill Z, Roy K et al. Impulse oscillometry in COPD: identification of measurements related to airway obstruction, airway conductance and lung volumes. Respir Med 2009; 103:I3643. http://dx.doi.org//0.1016/j.rmed.2008.07.014 